\title{
FATORES GEOGRÁFICOS E CULTURÃ DE GRAU SUPERIOR
}

(Influência de fatores geográficos na cultura superior do Rio Grande do Sul, especialmente na jurídica)

\author{
LOURENÇO MÁRIO PRUNES \\ Desembargador do T. J. do Rio G. do Sul. \\ Professor de Geografia Humana na Faculdade \\ de Filosofia de Porto Alegre
}

RESUMO :

Academias frequentadas, durante o Império, pelos riograndenses do Sul - Surgimento das escolas superiores gaúchas - A instalação da Relação de Pôrto Alegre - Origem dos nossos magistrados Predomínio, em certa época, dos juristas oriundos do Norte - Causas que determinaram a vinda, para o Sul, de bachareis nordestinos - Relação dos desembargadores, desde 1874, com a designação da naturalidade (mais de trinta por cento filhos de outras Províncias ou Estados).

Iniciou-se o povoamento do Rio Grande do Sul duas centúrias depois da ocupação do litoral Nordeste e Leste pelos colonizadores reinícolas; sòmente quando adentrado o século XVIII, tendo já aquelas outras regiões brasileiras vivido longos e dramáticos períodos de lutas e completado mais de um ciclo econômico, é que o Continente de São Pedro testemunhou o alvorecer das aldeias e estâncias na orla das lagoas e do Jacuí. Injunções geográficas fizeram com que o espaço medianeiro entre Laguna, - ponta de lança meridional dos paulis- 
tas, - e a Colônia do Sacramento, - cabeça de ponte isolada dos lusos, - permanecesse dilatado tempo como terra de ninguém, apenas sacudido de quando em vez pelo tropel das vacarias. Os circunjacentes experimentavam dificuldades em dominá-lo, pois por um lado, como barragem traiçoeira, alongavam-se duas penínsulas areientas, desabrigadas e sem angras; pelo Norte soerguia-se o planalto, não muito elevado mas abrupto, sulcado de fundos vales, eriçado de cordões ásperos e revestido de mata densa; pelo oeste, corriam rios caudalosos, mas desnivelados por degraus que impediam a inter-comunicação do mar com as paragens mediterrâneas. Sôbre difícil a penetração, arreceiavam-se os que beiravam as planícies, porque adivinhavam-nas como arena de embates. Assim as belas pradarias de campos dobrados, que se alongam ao sul do eixo Jacuí-Ibicui até morrer na fímbria oceânica da antiga Banda Oriental, durante muito tempo foram como que terra de ninguem, fronteira deserta a separar duas soberanias tementes uma da outra. Cornélio Tácito, enumerando os limites da Germânia, diz que em certo trecho esta separa-se dos vizinhos pelo mutuo metu. Lusitanos e castelhanos tambem apartavam-se uns dos outros, aqui nestas latitudes, pelo mútuo mêdo, deixando de permeio as coxilhas de pastagens nativas, ideais para as lidas da pastorícia, assim como para as cargas de cavalaria. Finalmente, ao cabo de sucessivas lutas e tratados, angustiou-se o âmbito dos "campos neutrales", até reduzir-se à linha geométrica ideal que liga e perlonga os álveos dos rios Jaguarão e Quaraí. Integrou-se a Capitania de São Pedro no ecúmeno brasileiro; loureceram as lavouras na bacias do Jacuí e a gadaria reprimiu-se nos compartimentos dominicais das sesmarias, consolidando a conquista política e econômica das colinas meridionais. Êste precioso espaço geográfico, dos mais dadivosos da terra brasileira, muito demoraria, contudo, para gozar de instantes duradouros de paz. Na verdade, ainda por quase mais de dois séculos não conheceria tranquilidade, alternaria guerra áspera com períodos de precário armistício. Abalaram-no alaridos de guerra, quando não o fragor de batalhas que soldaram um quinhão de glória em cada topônimo de rio ou de coxilha. Os instantes de calma semelhavam compassos de 
espera, até que os céus platinos, toldados de ameaças, desencadeassem novos raios, que cumpria aparar e quebrantar. Os plantadores de trigo do leste e os rudes pastores que disseminavam corajosamente pelas sesmarias do oeste e sul revezavam os trabalhos de campo com as fainas da guerra; eram soldados e campeadores ao mesmo tempo, recrutados entre os lidadores eqüestres de todas as categorias. 0 homem, segurando a rabiça do arado, ou manejando as boleadeiras e esgrimindo a lança, quase não podia cuidar das letras.

O litoral brasileiro do norte avantajava-se de dois séculos de idade sôbre nós e, ademais, acumulara riquezas e experiências econômicas, e, sobretudo, passara a gozar de ambiente mais sossegado, já que as rivalidades de Espanha e Portugal transmudaram o Continente de São Pedro em abcesso de fixação, num tentame para solver a diátese colonialista. Tais circunstâncias favoreceram, não muito depois da vinda de D. João VI e da Independência, o nascimento de cursos de estudos superiores em Olinda, São Paulo, Rio de Janeiro e Salvador. 0 Rio Grande do Sul, Província do Império e depois Estado da Federação, precisaria aguardar cerca de oitenta anos para lançar as primeiras escolas de grau superior. Não dispunhamos, assim, de forja doméstica para temperar as armas do espírito, e, por outro lado, poucos dos nossos conterrâneos podiam dirigir-se para os educandários de outras Províncias ou de Portugal, porque durante prolongado tempo o Rio Grande viveu isolado, separado do Brasil e do mundo pelos cordões arenosos do litoral, com uma única entrada e saída, que transformava as viagens numa aventura, que não se podia experimentar muitas vezes. Nossos capitães de guerra possuiam no geral apenas rudimentos de humanidades. Antes da Independência alguns andaram por Lisboa, onde frequentaram o Colégio dos Nobres (Manoel Corrêa da Câmara foi um dêles); a grande maioria, porém, não teve oportunidade de frequentar bancos de nível universitário. Sua formação guerreira iniciava-se no geral na infância; muitos pelejaram ainda impúberes (Manoel Marques de Souza, conde de Pôrto Alegre, por exemplo, aos treze anos fez seu noviciado nos entreveros). No primeiro Im- 
pério propiciaram-se maiores oportunidades aos nossos patrícios destinados à carreira das armas, tendo não poucos obtido matrícula na Escola Militar do Rio de Janeiro. Fundar-se-ia mais tarde, em Pôrto Alegre, um curso superior militar, cuja funcionamento abriu novas perspectivas para a mocidade do Rio Grande do Sul. Tambem a Escola de Guerra do Rio Pardo, instalada em 1898, registra um instante significativo, se bem que efêmero, na história da cultura do nosso Estado.

O progresso material de alguns núcleos urbanos e a criação de uma classe abastada na campanha facilitaram meios para que alguns jovens fossem cursar escolas superiores do Norte ou de Portugal. Os fillhos dos burgueses endinheirados de Pôrto Alegre e de Rio Grande e dos fazendeiros donos das sesmarias precisavam pagar tributo às armas, como obrigação natural e constante, mas a ambição de cultura levou a Coimbra, na primeira metade do século passado, não menos de quinze riograndenses, entre os quais alguns desfrutariam mais tarde de evidência intelectual ou política. Foram êles José Saturnino da Costa Pereira, Cândido Rodrigues Alves de Figueiredo, Cândido Baptista de Oliveira, José de Araujo Ribeiro, Antônio Rodrigues Fernandes Braga, Joaquim Vieira da Cunha, Antônio Vieira Braga, José Vieira Braga, Pedro Rodrigues Fernandes Chaves, Joaquim José da Cruz Seco, Francisco de Sá Brito Junior, Manuel Vieira da Cunha, Tristão Soares de Paiva, Rafael de Araujo Ribeiro, João Baptista da Silva Pereira Junior e Joaquim Lopes dos Santos. O pôrto-alegrense Cândido Baptista de Oliveira, além de bacharelar-se em matemática e filosofia em Coimbra, diplomou-se mais tarde pela Escola Politécnica de Paris e em seu regresso lecionou a cadeira de mecânica na Academia Militar do Rio de Janeiro (1827), figurando entre os primeiros rio-grandenses, - senão o primeiro, - a ocupar uma cátedra universitária; e seu renome de cientista não encontraria émulo, no seu tempo, entre os conterrâneos. 0 rio-grandino Pedro Fernandes Chaves, que viria de Coimbra para São Paulo, foi desembargador da Relação de Pernambuco, presidente da Província da Paraíba, deputado, senador e ministro plenipotenciário. Antônio Rodrigues Fernandes Braga, por sua vez, de- 
sempenhou o cargo de presidente da Província no início da Revolução Farroupilha, enquanto que José de Araujo Ribeiro fez bela carreira diplomática e ainda desempenhou os cargos de senador e de presidente das Províncias de Minas Gerais e do Rio Grande do Sul. Dez outros rio-grandenses frequentariam os cursos de Coimbra, na segunda metade do século: Manoel Correia de Melo, Augusto Carlos de Araujo Bastos, Luís Felipe Alves da Nobrega, Eduardo Ernesto de Araujo, Artur Pinto da Rocha, Júlio da Costa Cabral, João da Nobrega Araujo, Manuel José Gomes Braga, Álvaro Pereira Soares e Antônio Luís Gomes da Silva. Aliás já muito antes, entre 1767 e 1791, a Universidade coimbrense diplomara seis moços nascidos na Praça Nova da Colônia do Sacramento, alguns deles oriundos de famílias açorianas do Rio Grande de São Pedro: Francisco Xavier de Lima, Tomé Barbosa de Figueiredo, Joaquim Roberto de Azevedo, Manuel Eufrásio de Azevedo Marques, Felício José Barbosa e Hipólito José da Costa Pereira.

Nos primeiros tempos, mesmo depois da Independência, quase nåo havia função para advogado ou bacharel em nossa terra. Já Saint-Hilaire informa em seu "Voyage à Rio Grande do Sul" que os criminosos da Capitania eram remetidos e julgados no Rio de Janeiro; a maior parte ficava presa, sem julgamento. Esclarece: "Como nessa distante cidade (Rio de Janeiro) era difícil reunir provas suficientes para os condenar e como ninguem ficasse contra êles, era hábito deixá-los durante vários anos nas prisões, terminando por dar-lhes liberdade sem julgamento prévio". Cessou êsse regime no govêrno do Marquês de Alegrete, depois de 1810 , com a criação de uma Junta Criminal, que deveria reunir-se anualmente, e integrada pelo general governador, pelo ouvidor e pelos juizes-de-fora de Pôrto Alegre, Rio Grande e Rio Pardo e de dois desembargadores com residência na séde. A Junta "passou muitos anos sem se reunir e quando se reunia era por pouco tempo"; disolveu-se em 1820, depois de julgar quatro indivíduos entre os duzentos que se acotovelavam nas prisões de Pôrto Alegre (Pôrto Alegre com dez mil habitantes e duzentos presos: em idêntica medida a Correção e os xadrezes distritais de hoje deveriam abrigar nove mil 
criminosos... e os nossos juizes ainda se queixam...) Por outro lado, as causas civeis, em grau de recurso, seguiam para julgamento na Relação do Rio de Janeiro e lá se eternizavam. Sòmente depois de decorrido meio século é que se instalou a Relação de Pôrto Alegre, prometida na Constituição Imperial de 1824.

Apesar de tudo isso os nosso jovens procuraram adquirir cultura, nem mesmo os atemorizava a viagem marítima. Instalado o curso jurídico de São Paulo no ano de 1828, para lá se transferiram diversos rio-grandenses, quatro dos quais fizeram parte da primeira turma que colou grau no planalto piratiningano. Eram êles Joaquim Vieira da Cunha, que seria juiz de Rio Pardo; Joaquim José da Cruz Sêco, primeiro juiz de Pelotas; Vicente José da Maya, segundo juiz de Pelotas; Francisco de Sá Brito Junior, primeiro juiz da comarca de Missões, empossado no têrmo de Alegrete. Exceto o terceiro, os outros vieram transferidos de Portugal, porque a reação absolutista, encarnada em D. Miguel, fechara a velha Universidade lusitana.

Aumentou extraordiàriamente, sobretudo na segunda metade do século passado, o movimento rumo à Faculdade de Direito de São Paulo, transformados os nossos jovens comprovincianos, lá e aqui, em arautos das idéias republicanas, influenciados, por sem dúvida, pela tradição farroupilha. Pelos ban$\cos$ do velho convento de São Francisco passaram vultos eminentes da nossa história, a começor pelas figuras consulares de Gaspar Silveira Martins, Júlio de Castilhos, Pinheiro Machado e Assis Brasil. Alguns seguiam para mais longe, frequentaram a Escola de Olinda, cujo currículo também se baptizara em 1828 no vetusto casarão de São Bento. Transferido ulteriormente o curso para Recife, na capital pernambucana estudou o bageense Fernando Luís Osório, que lá bateu em virtude de conflito em que se envolvera em São Paulo, e que na idade madura viria a ocupar uma das cátedras da mais alta côrte de justiça nacional. Igualmente em Recife formou-se Antônio Augusto Borges de Medeiros, outro varão excelso dos pagos.

Na Faculdade de Medicina do Rio de Janeiro diplomaram- 
se dezenas de rio-grandenses, entre outros, em meados do século passado, o dr. José Antonio do Vale Caldre e Fião, o dr. Francisco Ferreira de Abreu (mais tarde barão de Terezópolis e que exerceria o cargo de diretor daquela escola) e o dr. José Martins da Cruz Jobim, futuro senador, sendo que os dois últimos, seguindo na esteira de diversos comprovincianos, também frequentaram cursos médicos em Paris. Em certa época manifestaram os rio-grandenses preferência por Salvador, em parte atraidos pelos seus cursos de medicina, farmácia e odontologia, em parte temerosos da febre amarela, que grassava no Rio de Janeiro. Aliás as denominadas moléstias tropicais, - que englobavam naquele tempo muitas de etiologia desconhecida, relacionada com carências alimentares, - devem ter concorrido para que a nossa gente evitasse as áreas dominadas pelo flagelo. A malária, por exemplo, pràticamente ignorada, naquele tempo, no Rio Grande do Sul, levou muitos estudantes a fugirem do litoral paludoso; daí a preferência por São Paulo, e mais tarde Ouro Preto, onde cursavam farmácia e engenharia de minas. Os nossos conterrâneos elegiam o planalto onde $o$ anófele, - vector das febres malígnas, - não tinha, para prosperar, as mesmas facilidades que encontrava nas planícies costeiras, e porque lá as condições térmicas, graças ao jôgo da altitude, não se disttanciavam muito das propiciadas pela atmosfera do torrão natal.

Apesar da dificuldade de comunicações entre o Rio Grande do Sul e as demais Províncias (a estrada de ferro só nos ligaria ao centro já neste século), o que impunha aos nossos moços os riscos da viagem marítima, com a transposição sempre inquietadora da barra, as escolas platinas, - cursos superiores muito mais antigos do que os brasileiros, - nunca atraiam estudantes rio-grandenses. Havia a facilidade da língua, no geral bem entendida quando não bem falada pela gente da fronteira, e relativa comodidade nas comunicações, tanto que em certa época os habitantes da campanha rio-grandense melhor conheciam Montevidéo e Buenos Aires, onde habitualmente fazias suas compras, do que a própria Pôrto Alegre, mas as lutas que mantivemos com os Estados platinos, a lembrança e receio 
da velha hostilidade e, mormente, a quase permanente guerra civil que inquietou, com pequenos armistícios, durante todo o século passado, a vida da Argentina e da República Oriental do Uruguai, impediram que os nossos jovens pudessem ingressar nas escolas das duas grandes capitais do Prata. Procuraramnas, porém, mais tarde, os nossos médicos, já formados, com objetivos de aperfeiçoamento cultural, frequentando clínicas de profissionais famosos. Tal procura se faz sentir ainda em nossos dias, mas com características individuais, semelhante à corrente que em certa época dirigia-se para o ocidente europeu e, mais recentemente, para os Estados Unidos.

Existiam antes algumas boas escolas de humanidades, a começar pelo Liceu D. Afonso, que funcionou desde 1859, e a Escola Normal, instituida em 1869, mas as escolas superiores, excetuando as de guerra, só começaram a germinar em fins do século passado, datando de 1896 a Escola de Engenharia e a de Medicina de 1898, englobando esta cursos instalados um pouco antes (o de Farmácia e o de Partos) e sòmente em 1900 surgiria a Faculdade de Direito. Uma década depois fundar-se-ia a de Agronomia e Veterinária, e só quarenta anos mais tarde inauguraram-se a de Economia e Administração (antes anexa à de Direito) e a de Filosofia, Ciências e Letras. As duas últimas, assim como os estabelecimentos componentes da novel Pontifícia Universidade Católica, aproveitaram, na constituição do corpo docente, material humano na quase totalidade riograndense e diplomado por escolas tambem rio-grandenses. Fato semelhante aconteceu com as Faculdades de Direito e Farmácia de Pelotas e Santa Maria. Naqueles três primeiros cursos superiores os catedráticos fundadores em bôa parte eram riograndenses, mas, - como não podia deixar de ser, - todos diplomados em escolas do centro e norte, predominando entre os fundadores da Faculdade de Medicina os formados no Rio de Janeiro e Bahia (Protásio Alves, Alfredo Leal, Carvalho Freitas, Arlindo Caminha, Cristiano Fischer e João Daudt Filho), entre os da Escola de Direito os diplomados em São Paulo e Recife (desembargadores Carlos Thompson Flores e Epaminondas Brasileiro Ferreira e drs. Antônio Fausto Neves de Souza, 
Manoel André da Rocha, Manoel Pacheco Prates, Plínio de Castro Casado, José de Almeida Martins Costa Junior, Timóteo Pereira da Rosa, Rossidônio da Cunha, Leonardo Macedônia, Alcides Cruz, Sebastião Leão e James Darcy). Já a Escola de Engenharia, que mais tarde tomaria as proporções de verdadeira universidade técnica, é filha da antiga Escola Militar de Pôrto Alegre, pois exceto o chefe inicial da novel instituição, engenheiro civil Álvaro Nunes Pereira, os seus demais professores eram militares (João Simplício Alves de Carvalho, João Vespúcio de Abreu e Silva, Juvenal Otaviano Muller e Lino Carneiro da Fontoura). $O$ próprio dr. João José Pereira Parobé, filho de São João do Norte, grande propulsor do educandário, era oficial reformado, com curso de Engenharia Militar de Pôrto Alegre.

$\mathrm{O}$ número relativamente pequeno de advogados, médicos e engenheiros rio-grandenses, e, mais do que isso, o progresso acelerado do Estado, estimulavam naturalmente a vinda de profissionais, naturais de diferentes regiões do Brasil. Por outro lado, as guerras e revoluções trouxeram-nos muitos elementos, integrados no Exército, que aqui se fixaram, através das guarnições estáveis então existentes. Eram sobretudo engenheiros e médicos, alguns de nome ilustre, que constituiram família, dando origem a troncos que ainda hoje se reproduzem. A organização da justiça, então nacional, fazia com que viessem para aqui, transferidas, personalidades eminentes da Magistratura. Uns passaram ràpidamente pelas comarcas, outros permaneceram de modo duradouro, tendo seus nomes insculpidos na história dos nossos pretórios.

Fato significativo foi a instalação, a 3 de fevereiro de 1874, da Relação de Pôrto Alegre, que equivalia, por suas atribuições, ao nosso atual Tribunal de Justiça. Foi seu primeiro presidente o conselheiro João Baptista Gonçalves de Campos, visconde de Jary, com Real Grandeza, nascido no ano de 1814 na Capitania do Grão Pará e diplomado em 1840 na escola de Olinda. Integravam inicialmente a Relação os desembargadores Julio Cesar de Bittencourt, Antônio Augusto Pereira de Almeida, Luiz 
José de Sampaio, Adriano José Leal, Ignácio José de Mendonça Uchôa e Luiz Queiroz Barros. Temos aí pernambucanos, piauienses e rio-grandenses do norte, sendo de notar que quase todos êles concluiram suas carreiras de magistrados no Supremo Tribunal Federal. Pouco depois ainda viriam para a mesma Relação o maranhense José de Almeida Martins Costa (diplomado em Olinda), o piauiense Antônio de Souza Martins (natural de Oeiras, capital do Piauí, e tambem diplomado em Olinda), e já na República, em 1890, o pernambucano Hermínio do Espírito Santo, que coroaria seus dias de magistrado como presidente do Supremo Tribunal Federal. Mais tarde, reorganizado o Tribunal local, ainda ocuparia a sua presidência o paranaense James de Oliveira Franco e Souza (natural de Morretes), mas contemporâneamente tomaram assento no mesmo os gaúchos Antônio Augusto Borges de Medeiros, Carlos Thompson Flores e Antônio Augusto Ribas...

Com a República, principalmente depois da Revolução de 1893, verificou-se extraordinária afluência de juristas nordestinos. Estadualizada a justiça, vinham aqueles moços, alguns recem diplomados, com ânimo de empreender vida nova entre nós. Nos movimentos migratórios, seja de grupos, seja de indivíduos, atuam sempre causas de expulsão e de atração. Diplomados na mor parte em Recife, vinham aquêles advogados, ou do próprio Pernambuco, ou dos Estados vizinhos, e eram indiretamente expulsos pela sêca. Fossem ou não naturais das zonas calcinadas pelos flagelos cíclicos, sentiam as suas consequências, já que minguavam as possibilidades de trabalho no interior sertanejo e nas capitais as ocupações remuneradas atingiam o nível de saturação. 0 empobrecimento ambiente impunha-lhes o abandono da querência e a procura de outras terras. Os mais comodistas pensavam na Capital Federal, pólo magnético que até hoje atrae brasileiros de todos os quadrantes. Os mais corajosos olhavam para bem longe, atiravam o olhar para o sul, semilendário e semidesconhecido, pouco tranquilo mas oferecendo possibilidades de êxito profissional e material. Empreendendo estirada viagem marítima, deixando o sertão ou a cidade litorânea, aqui aportaram dezenas de nordes- 
tinos, senhores de bom patrimônio cultural. Ao Rio Grande do Sul não coube um restolho de catástrofe ou um saldo de tormenta, mas excelentes exemplares de cultura, probidade e inteligência. Não vai nesta afirmativa um exagero embebido em generosidade ou um gesto de simpatia de hospedeiro para hóspedes. Basta lembrar os nomes de Manoel André da Rocha e de Francisco Ribeiro Dantas, dois rio-grandenses do norte que tanto enobreceram a toga de magistrados quanto deram brilho à cátedra em que pontificaram. Cerca de cem desembargadores passaram pelo nosso Tribunal de Justiça, a começar do ano de 1874, data em que se instalou a Relação. Até o ano de 1900, de trinta desembargadores nomeados, pelo menos vinte e cinco eram nortistas. Depois aumentou a participação dos riograndenses: de oitenta e dois juizes empossados entre 1892 e dezembro de 1953 (incluindo os falecidos, os aposentados e os em atividade) seis são pernambucanos, cinco baianos, três riograndenses do norte, três fluminenses, dois maranhenses, dois paraibanos, dois cearenses, um paranaense, um sergipano, um alagoano, um paulista, úm piauiense e um carioca, totalizando vinte e nove filhos de outros estados, enquanto são cinquenta e dois os rio-grandenses do sul. Nos últimos tempos quase que se estancou a fonte que tinhamos no setentrião brasileiro. Por um lado as melhores perspectivas em sua própria terra, por outro lado a auto-suficiência cultural e profissional do Rio Grande do Sul (hoje com três faculdades de direito), não mais permitem transladações densas, como ocorria em outros tempos.

Nas décadas anteriores predominavam nos lugares de evidência política e administrativa os rio-grandenses formados em outros Estados. Basta dizer que entre os civis, naturais do Rio Grande do Sul, que foram ministros de Estado na República, a grande maioria se formou em São Paulo ou no Distrito Federal: Demétrio Nunes Ribeiro, Homero Baptista, Carlos Maximiliano, Uladislau Herculano de Freitas, Ildefonso Simões Lopes, Rivadavia da Cunha Corrêa, José Barbosa Gonçalves, Joaquim Francisco de Assis Brasil, Oswaldo Aranha, Lindolfo Collor, Francisco Maciel Junior e Joaquim Pedro Salgado Filho. Nos últimos tempos, porém, já predominavam os forma- 
dos em Pôrto Alegre: Getúlio Dorneles Vargas, Joaquim Maurício Cardoso, João Neves da Fontoura, Adroaldo Mesquita da Costa e Clovis Pestana. E atualmente nos mandatos legislativos, nas cátedras universitárias e na magistratura é quase total a dominação dos egressos das escolas superiores do Rio Grande do Sul.

Para elaborar êste trabalho, minha pesquisa foi a de garimpeiro apressado, mais diligente do que hábil, que tendo um compromisso a cumprir, saiu, a correr celeradamente pelos veeiros mais acessíveis. Limitei-me, aliás, a arrolar fatos que dizem respeito tão sòmente à cultura de grau superior, tècnicamente falando, pondo à margem as manifestações puramente intelectuais e artísticas, porque de outra forma o estudo extravasaria do âmbito traçado e exigiria o esmerilhar de múltiplas facetas. Um labor demorado e paciente revelaria sem dúvida novos e ricos filões e refulgentes pepitas. Muitas localidades do interior, por exemplo, conservam a tradição de médicos "baianos", que aqui se fixaram, trazidos por corpos do Exército; outros burgos da campanha recordam engenheiros militares que construiram pontes e estradas, que ajudaram a implantar a rêde telegráfica e a ferroviária, que fizeram levantamentos topográficos, que demarcaram as fronteiras, que desenharam mapas, que mediram rios, e determinaram a altitude de colinas, cêrros e serras. Bôa parte deles vinha da costa ou mesmo do coração do Brasil tropical. Muitos têm os nomes gravados em placas pregadas nas ruas, avenidas, estações ou obras d'arte que se espalham pelos recantos urbanos e rurais. Outros ficaram em meio do caminho, não chegaram às culminâncias da vida social; alguns perderam-se no anonimato, com os apelidos diluidos e misturados na poeira do tempo. Ninguém, porém, deixou de carregar a sua pedra, todos ajudaram a estruturar, no espaço de poucas gerações, - nos pretórios, nos hospitais, nas cátedras, nos trabalhos do espírito e nos monumentos materiais, - a vida cultural da Província de São Pedro do Sul. 


\section{APÊNDICE:}

\section{NOMINATA DOS DESEMBARGADORES DA JUSTIÇA DO RIO GRANDE DO SUL (COM AS DATAS DAS INVESTIDURAS)}

\section{Desembargadores da Relação de Pôrto Alegre:}

João Batista Gonçalves de Campos - 3-2-1874; Júlio Cesar Berenguer de Bitencourt - 3-2-1874; Luiz José de Sampaio - 3-2-1874; Antônio Augusto Pereira da Cunha - 3-2-1874; Adriano José Leal - 3-2-1874; Ignácio José de Mendonça Uchôa - 3-2-1874; Luiz Corrêa de Queiroz Barros - 3-2-1874; João da Costa Lima e Castro - 11-3-1876; Antônio de Souza Martins - 3-1-1883; Luiz Francisco da Câmara Leal - 1875; Antônio José Afonso Guimarães - 6-11-1877; José de Almeida Martins Costa - 10-3-1877; José de Araujo Brusque - 1877; Severino Alves de Carvalho - 1879; José de Araujo Rosa Danin - 1882; Daniel Acicly de Azevedo - 4-3-1881; Salustiano Orlando de Araujo Costa - 1882; Joaquim Guedes Corrêa Gondim - 1883; Frederico Dabney de Avellar Bro.. tero - 20-3-1887; Francelisio Adolfo Pereira Guimarães - 11-2-1888; Augusto Cesar de Medeiros - 11-1-1887; Luiz Holanda Cavalcanti de Albuquerque - 16-8-1890; Cesário José Chavantes - 24-1-1890; Bernardo Dias de Castro Sobrinho - 17-9-1890; Hermínio Francisco do Espírito Santo - 10-11-1890; Jerônimo Martins de Almeida - 21-5-1891; Luiz Jacinto Vergne de Abreu - 11-8-1891; Francisco Teixeira de Sá - 1891.

DESEMBARGADORES DO SUPERIOR TRIBUNAL DO ESTADO (HOJE TRIBUNAL DE JUSTIÇA), A PARTIR DE DEZEMBRO DE 1892, COM A DATA DA INVESTIDURA NA DESEMBARGADORIA E A INDICAÇÃO DA NATURALIDADE :

ABREVIATURAS: RS - Rio Grande do Sul; RN - Rio Grande do Norte; AL - Alagôas; BA - Bahia; CE - Ceará; DF - Distrito Federal; MA - Maranhão; PB - Paraíba; PR - Paraná; PI - Piauí; PE - Pernambuco; RJ - Rio de Janeiro; SE - Sergipe; SP — São Paulo.

Bernardo Dias de Castro Sobrinho - 31-12-1892 - MA; James de Oliveira Franco e Souza - 31-12-1892 - PR; Antônio Antunes Ribas 31-12-1892 - RS; Carlos Thompson Flores - 31-12-1892 - RS; Paulino Rodrigues Fernandes Chaves - 31-12-1892 - RS; Antônio Augusto Borges de Medeiros - 31-12-1892 - RS; José Vieira da Cunha - 1893 - RS; Epaminondas Brazileiro Ferreira - 14-11-1894 - RS; Tito Prates da Silva - 5-9-1896 - RS; Alcebiades Cavalcanti de Albuquerque - 11-121897 - PE; Bernardino de Sena Costa Feitosa - 10-5-1901 - BA; Manoel André da Rocha - 12-2-1903 - RN; Melchisedch Mathuzalem Cardoso - 1904 e 29-5-1917 — SE; Jardelino Gonçalves de Senna - 1904 - 
BA; Pedro Afonso Mibieli - 1906 - RS; José Valentim do Monte 7-5-1907 - AL; Manoel de Escobar Junior - 23-11-1912 - RS; Manoel Orfelino Tostes - 6-6-1914 - RS; Armando Azambuja - 2-3-1915 RS; Arsenio da Silveira Gusmão - 1917 - BA; José Lucas Alvares Filho - 1917 - RN; Luiz de Melo Guimarães - 13-9-1920 - RS; Augusto Guarita - 30-5-1921 - PB; Caio da Cunha Cavalcanti - 8-6-1921 -PE; José Bernardo de Medeiros Junior - 17-4-1921 - RN; Florêncio de Abreu e Silva - 9-8-1924 - RS; Gomercindo Taborda Ribas - 12-6-1925 - SP; Paulino Coelho de Souza - 2-10-1928 - RS; João Magalhães 12-12-1928 - PI; Espiridião de Lima Medeiros - 23-2-1931 - PB; La Hire Guerra - 20-3-31 - RS; Joaquim Américo Carneiro Pereira 7-4-1932 - CE; Oswaldo Caminha - 27-7-1932 - RS; Cesar Dias 2-12-1932 - RS; João Antônio Alves Nogueira - 7-1-1933 - RS; Samuel Figueiredo da Silva - 7-1-1933 - RJ; Inocêncio Borges da Rosa - 28-7-1933 - RS; Anapio Jobim - 24-5-1934 - RS; Hugo Candal 4-3-1935 - RS; Leonardo Ferreira da Silva - 4-3-1935 - RS; Antônio Vieira Pires - 26-6-1935 - RS; Francisco Rodolpho Simch - 26-6-1935 - RS; João Amorim de Albuquerque - 26-6-1935 - RS; Luiz de Freitas e Castro - 5-7-1935 - RS; Admar Ribeiro Barreto - 28-11-1935 - RS; Elziário Vieira Nunez - 6-6-1936 - RS; Antônio Fernandes da Silveira Carvalho - 17-6-1936 - PE; Alvaro Leal - 5-12-1936 - PE; Carlos Heitor de Azevedo - 5-6-1937 — RS; Homero Martins Baptista - 17-9. 1937 - RS; Nésio de Almeida - 2-4-1938 - RS; João Pereira de Sampaio - 24-5-1938; Erasto Roxo de Araujo Corrêa - 15-7-1938 - DF; Dyonisio Marques - 20-7-1938 - RS; Augusto Loureiro Lima - 31-81938 - RS; João Pinto Martins de Oliveira - 22-9-1938 - BA; João Soares - 6-4-1938 - RS; João Solon Macedonio Soares - 24-5-1938 RS; Jorge Moojen da Rocha - 31-8-1940 - RS; Celso Afonso Soares Pereira - 30-4-1941 - MA; Ernesto Candal - 5-3-1941 - RS; Silvio Wallace Duncan - 27-7-1942 - RJ; Edmundo Dantas - 27-7-1942 RS; Décio Pelegrini - 8-9-1944 - RS; João Clímaco de Melo Filho 3-9-1945 - RS; Maurílio Alves Daiello - 5-5-1949 - BA; Coriolano Albuquerque - 8-4-1949 - RS; Cândido Corrêa de Paiva - 19-4-1949 RS; Ney da Silva Wiedemann - 28-4-1949 - RS; Moreno Loureiro Lima - 4-5-1949 - RS; Arthur Oscar Germany - 10-5-1950 - RS; Claudino Gayer - 10-5-1950 — RS; Darcy Pinto - 7-5-RS; Eurico de Souza Leão Lustosa - 4-5-195 1 - PE; Lourenço Mário Prunes - 5-9-1951 - RS; Baltazar Gama Barbosa - 5-12-1951 - RS; Ciro Pestana - 20-3-1952 - RS; Oldemar Nogueira da Gama de Toledo - 20-3-1952 - RS; Crisanto de Paula Dias - 20-3-1952 - RS; Antônio Fernandes da Cunha Lima - 18-3-1953 - PE; Eloy José da Rocha - 31-4-1953 - RS; Carlos Thompson Flores - 3-6-1953 - RS. 